\title{
PEMBERDAYAAN MASYARAKAT DAN MAHASISWA MELALUI PROGRAM PARFIMAS (PERBAIKAN FASILITAS MASYARAKAT) DI DESA WONOMULYO KABUPATEN BULUNGAN BERBASIS REVOLUSI MENTAL GERAKAN INDONESIA MELAYANI
}

\section{Community Empowerment And Students Through The Program Parfimas (Community Facilities Improvement) In The Village Wonomulyo Bulungan-Based Mental Revolution Indonesian Movement Serve}

\author{
Daud Nawir $^{1^{*}}$, Endik Deni Nugroho ${ }^{2}$, Achmad Zultan $^{3}$ \\ 1,3 Jurusan Teknik Sipil, Fakultas Teknik, Universitas Borneo Tarakan \\ ${ }^{2}$ Jurusan Pendidikan Biologi, Fakultas Keguruan dan Ilmu Pendidikan, Universitas Borneo Tarakan \\ Jl. Amal Lama No. 1, Tarakan \\ *e-mail Korespodensi: daudnawir@gmail.com
}

\begin{abstract}
ABSTRAK
Desa wonomulyo merupakan desa dengan jumlah penduduk yang terbanyak ke empat di kecamatan Tanjung Palas Timur dengan luas wilayah $14 \%$ dari $67.777 \mathrm{~km}$. Desa Wonomulyo terdiri dari 8 Rt yang mayoritas ketua Rt memiliki Pendidikan jenjang SD-SMP, dan menjadi permasalahan tersendiri terkait administrasi dan pengelolaan informasi publik serta mampu mengajak masyarakat untuk menyadarkan masyarakat untuk memiliki nilai integritas dan gotong royong dengan memberikan informasi-informasi publik yang melayani dan menjaga serta merawat fasilitas masyarakat. Melalui Program PARFIMAS (Perbaikan Fasilitas Masyarakat) dengan mengintegrasi pemberdayaan masyarakat dengan mahasiswa melalui pengabdian kuliah kerja Nyata berbasis revolusi mental dengan Gerakan Indonesia Melayani, diharapkan mampu menyadarkan dan memberikan informasi-informasi tentang pelayanan publik dan fasilitas fasilitas desa dapat di manfaatkan oleh masyarakat dengan baik. Tujuan PKM KKN Universitas Borneo Tarakan Melatih masyarakat dan memberikan pembekalan ilmu pengetahuan untuk mengembangkan potensi yang dimiliki, baik potensi alam maupun potensi yang ada di dalam diri masyarakat. Melalui gerakan Indonesia Bersih PKM Revolusi Mental Universitas Borneo Tarakan Menuju kesadaran dan kepedulian baik masyarakat maupun pemerintahan desa terhadap pelayanan publik melalui Revolusi Mental gerakan Indonesia Melayani yang diimplementasikan pada contoh Perbaikan informasi public terkait informasi pelayanan masyarakat, membuat papan informasi masyarakat, dan memperbaiki fasilitas masyarakat.
\end{abstract}

Kata Kunci: Fasilitas Masyarakat, Pemberdayaan, Kuliah Kerja Nyata, Revolusi Mental, Gerakan Indonesia Melayani, Desa Wonomulyo

\begin{abstract}
Wonomulyo Village is a village with the highest number of inhabitants in Tanjung Palas Timur Subdistrict with an area of $14 \%$ of $67,777 \mathrm{~km}$. Wonomulyo Village consists of 8 Rt which the majority chairman Rt has a level education elementary school - junior high school, and become Its own problems related to the administration and management of public information and are able to invite people to realize the community to have the value of integrity and mutual cooperation by providing information on the public that serves and Maintaining and caring for community facilities. Through the PARFIMAS Program (community facilities improvement) by integrating community empowerment with students through a real work lecture based on mental revolution with the Indonesian movement serving, it is expected to be able to realize and Provide information about public services and facilities of village facilities can be utilized by the community well. Objective PKM KKN University of Borneo Tarakan trains the community and provides a science supply to develop the potential that is owned, both natural and potential in the community. Through the Indonesia net movement of PKM Mental Revolution University of Borneo Tarakan towards awareness and concern both the public and the village government to public service through the Mental revolution of the Indonesian ministering movement implemented In the example of improving public information regarding public service information, creating a Community information board, and improving community facilities.
\end{abstract}

Keywords: community facilities, empowerment, real work lecture, Mental Revolution, Indonesian movement serving, Wonomulyo village

Daud. N., Endik. D.N., Achmad.Z., PEMBERDAYAAN MASYARAKAT... 


\section{PENDAHULUAN}

Jumlah Penduduk kecamatan Tanjung Palas Timur desa Wonomulyo pada tahun 2017 adalah 14.357 jiwa. Mata pencaharian mayoritas penduduk Kecamatan Tanjung Palas Timur desa Wonomulyo desa Wonomulyo adalah Pertanian dan Perkebunan. Untuk fasilitas pendidikan di kecamatan Tanjung Palas Timur desa Wonomulyo memiliki 4 sekolah dari 1 Playgorup, 1 TK, 1 SD Negeri, dan 1 SMP Negeri, dan belum memiliki fasilitas pendidikan yang lengkap dari jenjang SMA. pada bidang kesehatan kecamatan Tanjung Palas Timur desa Wonomulyo hanya memiliki 1 posyandu dan 1 Pustu untuk membantu kesehatan warga. Hal ini sungguh memprihatinkan karena tidak memiliki fasilitas kesehatan lain, baik berupa klinik dokter, puskesmas keliling, maupun bidan praktek. Selain itu juga banyak fasilitas falisitas seperti perpustakaan, jembatan, papan informasi publik tidak ada, Informasi Desa tidak ada, sarana olahraga rusak dan tidak terawat.

Kurangnya kesadaran masyarakat terhadap pengelolaan dan pelayanan masyarakat di desa Wonomulyo disebabkan mulai terkikisnya nilai nilai integritas dan gotong royong dalam bermasyarakat. Desa wonomulyo merupakan desa dengan jumlah penduduk yang terbanyak ke empat di kecamatan Tanjung Palas Timur dengan luas wilayah $14 \%$ dari $67.777 \mathrm{~km}$. Dengan potensi jumlah penduduk dan keragaman penduduk seharusnya menjadikan Desa Wonomulo lebih baik dalam pengelolaan fasilitas masyarakat dan merawat fasilitas publik untuk dimanfaatkan untuk kemajuan Desa Wanomulyo. Desa Wonomulyo terdiri dari 8 Rt yang mayoritas ketua Rt memiliki Pendidikan jenjang SD-SMP, dan menjadi permasalahan tersendiri terkait administrasi dan pengelolaan informasi publik serta mampu mengajak masyarakat untuk menyadarkan masyarakat untuk memiliki nilai integritas dan gotong royong dengan memberikan informasi-informasi publik yang melayani dan menjaga serta merawat fasilitas masyarakat. Melalui Program PARFIMAS (Perbaikan Fasilitas Masyarakat) dengan mengintegrasi pemberdayaan masyarakat dengan mahasiswa melalui pengabdian kuliah kerja Nyata berbasis revolusi mental dengan Gerakan Indonesia Melayani, diharapkan mampu menyadarkan dan memberikan informasi-informasi tentang pelayanan publik dan fasilitas fasilitas desa dapat di manfaatkan oleh masyarakat dengan baik.

Program pengabdian masyarakat Universitas Borneo Tarakan ini diharapkan mahasiswa dapat menggali potensi sumber daya alam dan mengembangkan sumber daya manusia yang tersedia. Akademika UBT bersama masyarakat dan para mitrakerja untuk bersinergi dalam mengembangkan dan mengimplementasikan program REVOLUSI MENTAL untuk menyelesaikan suatu permasalahan dan mewujudkan pembangunan berkelanjutan. Dimana revolusi mental ajakan mengubah cara pandang, pikiran, sikap perilaku yang berorientasi pada kemajuan dan kemodernan, sehingga Indonesia menjadi bangsa besar dan mampu berkompetisi dengan bangsa-bangsa lain.

Langkah selanjutnya berupa penetapan bidang strategis yang dapat dikembangkan di kecamatan Tanjung Palas Timur dengan fokus desa Wonomulyo, sehingga dapat meningkatkan informasi public dan pemanfaatan fasilitas desa secara masimal tersebut dalam bentuk pemberdayaan masyarakat. Untuk tujuan tersebut maka diusulkan program dengan tema: 
"Pemberdayaan Masyarakat Dan Mahasiswa Melalui Program Parfimas (Perbaikan Fasilitas Masyarakat) Di Desa Wonomulyo Kabupaten Bulungan Berbasis Gerakan Indonesia Melayani”. Oleh karena itu diperlukan suatu pemahaman mengenai kendala-kendala yang dihadapi dan faktor ketidakberdayaan masyarakat sebagai perencanaan dan pemecahan masalah secara partisipatif. Kegiatan pengabdian di kecamatan Tanjung Palas Timur dengan fokus desa Wonomulyo ini dibantu oleh berbagai pihak, seperti Bappeda Kalimantan Utara, BMPD kabupaten Bulungan dan Camat Tanjung Palas Timur.

Tujuan PKM KKN Universitas Borneo Tarakan Melatih masyarakat dan memberikan pembekalan ilmu pengetahuan untuk mengembangkan potensi yang dimiliki, baik potensi alam maupun potensi yang ada di dalam diri masyarakat. Melalui gerakan Indonesia Bersih PKM Revolusi Mental Universitas Borneo Tarakan Menuju kesadaran dan kepedulian baik masyarakat maupun pemerintahan desa terhadap pelayanan publik melalui Revolusi Mental gerakan Indonesia Melayani yang diimplementasikan pada contoh Perbaikan informasi public terkait informasi pelayanan masyarakat, membuat papan informasi masyarakat, dan memperbaiki fasilitas masyarakat.

\section{METODE}

Metode Pelaksanaan kegiatan Program kemintraan masyarakat (PKM) terbagi dalam beberapa tahap sebagai berikut :

a. Persiapan

1. PKM ini melibatkan mahasiswa sehingga melakukan wawancara untuk menjaring mahasiswa yang benar-benar komitmen terhadap program PKM yang ditawarkan, karena perlu keseriusan terlebih bhakti mahasiswa kepada masyarakat.

2. Adapun materi yang diberikan dalam sosialisasi PKM adalah tentang sosial budaya, pemberdayaan Peningkatan Layanan Pendidikan, wawasan revolusi mental, bidang administrasi baik administrasi negara maupun hukum administrasi dan Teknik perbaikan fasilitas masyarakat.

3. Survei/Observasi ke lokasi, mitra dan kelompok masyarakat yang dijadikan sasaran PKM.yaitu di Kecamatan Tanjung Palas Timur dengan fokus desa Wonomulyo.

4. Mengkomunikasikan program PKM dengan pemerintah daerah setempat, serta mitra lainnya

5. Membuat persetujuan dari kesepakatan kerjasama dengan Badan Pemberdayaan Masyarakat Desa (DPMD) Kabupaten Bulungan.

b. Pelaksanaan Pengabdian Kepada Masyarakat (PKM)

Kegiatan akan dilaksanakan menggunakan metode partisipatoris. Jadi, pelaksanaan program dilakukan dengan melibatkan masyarakat setempat dan mahasiswa Kuliah Kerja Nyata sebagai fasilitator. Untuk itu, diperlukan pendampingan dalam setiap kegiatan agar dapat diketahui dinamika dari kegiata tersebut sehingga dapat mewujudkan tujuan pemberdayaan. Adapun kegiatan yang di rancang adalah: (1) Bimbingan teknis/Pendampingan/Penyuluhan berupa aktivitas kegiatan Pertanian mahasiswa bersama masyarakat; (2) Aktivitas pendukung lainnya dalam rangka mengembangkan Kesadaran pelayanan publik dan menjaga fasiltas masyarakat berbasis Revolusi Mental Gerakan Indonesia melayani 


\section{c. Rencana Keberlanjutan Program}

Kegiatan Peningakatan kapasitas masyarakat di Kecamatan Tanjung Palas Timur desa Wonomulyo ini dapat terus menerus dengan memasukannya kegiatan pengabdian pada masyarakat yang dilakukan melalui kegiatan Pengabdian Kepada Masyarakat (PKM), sehingga dapat mengoptimalkan potensi mahasiswa setiap tahunnya. Melalui program pertanian, setelah implementasi program PKM terlaksana, diharapkan masyarakat lebih mandiri dalam mengolah potensi lokal yang ada, sehingga hasilnya lebih optimal. Selain itu, program ini juga diharapkan dapat membuat masyarakat menjadi lebih cerdas dan kaya akan ilmu yang menunjang pengolah potensi tersebut dan dapat mewujudkan kesejahteraan. Program kedua, peningkatan sumber daya manusia dalam bidang pendidikan. Program di bidang pendidikan ini diharapkan dapat meningkatan kesadaran akan pendidikan dan minat membaca pada generasi penerus sehingga dapat membuka wawasan dan ilmu pengetahuan. Sementara dalam bidang kesehatan, masyarakat diharapkan dapat meningkatan kesadaran akan pentingnya kesehatan. Dengan program peningkatan pelayanan masyarakat, peningkatan dan perbaikan fasilitas masyarakat, masyarakat diharapkan dapat lebih bertanggung jawab dalam pemeliharan lingkungan. Program terakhir yaitu pemetaan potensi lokal yang ada agar dapat menjadi refrensi dalam pembangunan desa.

Program ini diharapkan dapat dijadikan rekomendasi untuk pemerintah akan potensi yang dimiliki daerah Tanjung Palas Timur desa Wonomulyo, sehingga dapat membantu dalam pengelolaan potensi tersebut. Keberlanjutan program perlu di komunikasikan dengan pihak DPMD Kabupaten Bulungan, sehingga dapat dilakukan secara luas dengan melibatkan Tim Pengabdian Kepada Masyarakat (PKM)Universitas Borneo Tarakan dalam setiap kegiatan pelatihan dan pendampingan. Selain itu, tindak lanjut program yang berhubungan dengan pengelolaan program dilakukan dengan mengoptimalkan peran BPMD untuk mendukung keberlanjutan usaha yang dikembangkan, serta lokasi akan diusulkan sebagai Desa Binaan Universitas Borneo Tarakan.

\section{HASIL DAN PEMBAHASAN}

\section{a. Profil Desa Wonomulyo}

Luas wilayah DesaWonomulyo 1.111,25 Ha dimana $70 \%$ daratan dimanfaatkan sebagai lahan pertanian yang di manfaatkan untuk persawahan tadah hujan dan palawija. Iklim Desa Wonomulyo, sebagaimana desadesa lain di wilayah Indonesia mempunyai iklim kemarau dan penghujan, hal tersebuh mempunyai pengaruh langsung terhadap pola tanam pada lahan pertanian yang ada di Desa Wonomulyo Kecamatan Tanjung Palas Timur ini letak desa Wonomulyo dapat dilihat pada Gambar 1.

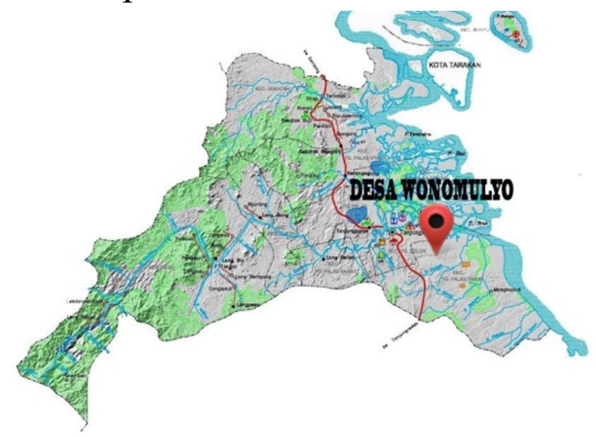

Gambar 1. Topografi Desa Wonomulyo, Kecamatan Tanjung Palas Timur, Bulungan

Wonomulyo adalah desa di Kecamatan Tanjung Palas Timur, Kabupaten Bulungan, Kalimanantan Utara. Desa ini memiliki 15 RT dan 2 RW. Di desa ini mayoritas penduduknya adalah transmigran yang berasal dari Pulau Jawa. Desa Wonomulyo 
berjarak sekitar $67 \mathrm{~km}$ dari Ibu Kota Kalimantan Utara. Mata pencarian masyarakat setempat adalah bertani. Desa Wonomulyo adalah daerah irigasi, luas daerah irigasi yang telah ditanami dan di kelola oleh masyarakat Desa Wonomulyo berdasarkan data monografi desa adalah sekitar 20 ha berupa irigasi semi teknis dan sawah tadah hujan seluas kurang lebih 15 ha. Daerah irigasi Wonomulyo ini belum ada bangunan pengambilan yang permanen.

Sejarah desa Wono Mulyo Jelarai Selor III dibuka pada akhir tahun 1993 dan ditempatkan penduduk pada awal tahun 1994 yang dipimpin oleh KUPT (Abdul Djabbar AP.BWS) dan dibantu oleh seorang staf KUPT (Muhammad Abadi). Penempatan penduduk tersebut dibagi menjadi 2 gelomban yaitu, gelombang I ditempatkan penduduk lokal (Punan dan Dayak), sedangkan gelombang II ditempatkan penduduk yang berasal dari Jawa Timur, Jawa Tengah dan Jawa Barat. Dengan jumlah kepala keluarga yang berdomisili di Jelarai Selor III sebanyak 240 KK yang terdiri dari 20\% dari masyarakat lokal/pribumi sedangkan yang $80 \%$ didatankan dari pulau Jawa.

Dalam pembinaan selama kurun waktu 1 tahun pemerintah masih dipimpin oleh Abdul Djabbar.AP.BWS dalam peraturan Depatermen Transmigrasi maka dibentuklah pemerintah desa persiapan dan pembenahan desa tersebut supaya diserahkan kepada pemerintah daerah tidak ada hambatan dan kendala lagi dan desa tersebbut mampu mandiri, maka para tokoh UPT Jelarai Selor III mengadakan pemilihan kepala desa persiapan, dengan singkat cerita terpilihlah Bapak Hasan Wagisan sebagai kepala desa persiapan dengan nama desa Wonomulyo. Wono yang dalam bahasa Jawa berarti Hutan, dan Mulyo berarti Mulya atau jaya. Jadi arti nama desa wonomulyo adalah desa hutan mulya. Pencaharian masyarakat Desa Wonomulyo dari tahun 1993 sampai saat ini adalah bercocok tanam/bertani, berdagang, karyawan swasta, wiraswasta dan buruh. Tetapi disini yang sangat menonjol adalah bercocok tanam sayur mayur dengan metode tumpang sari.

\subsection{Pelaksanaan Kegiatan}

Hasil pelaksanan kegiatan Integrasi Pemberdayaan Mahasiswa Sebagai kegiatan pengabdian Dengan Masyarakat Desa Wonomulyo Kabupaten Bulungan Melalui Program Perbaikan fasilitas Masyarakat berbasis Revolusi Mental Indonesia Melayani diuraikan dilakukan melalui beberapa tahap, yaitu: sosialisasi/ penyuluhan, dan pendampingan.

\section{Tahap Sosialisasi}

Tahapan sosialisasi merupakan kegiatan awal yang merupakan rencana kegiatan dalam rangka memberikan pemahaman, tujuan dan manfaat kegiatan yang akan dilakukan serta mengajak warga mengenal Revolusi mental dengan Gerakan Indonesia Melayani (GIM) adalah gerakan para penyelenggara negara dan masyarakat untuk meningkatkan perilakupelayanan publik berintegritas agar negara hadir melindungi kepentingan warganya sesuai dengan Pancasila dan UUD 1945. GIM merupakan gerakan yang berawal dari permasalahan masyarakat Indonesia dalam aspek pelayanan publik yang dinilai belum dapat memberikan pelayanan yang memuaskan kepada masyarakat sehingga mutu pelayanan yang disediakan pemerintah perlu ditingkatkan untuk menjadi lebih baik. Oleh karena itu, dengan adanya GIM diharapkan terjadi peningkatan pelayanan public pada setiap instansi terutama yang mempunyai tugas utama 
melakukan pelayanan umum.berdasarkan diagram di bawah ini.

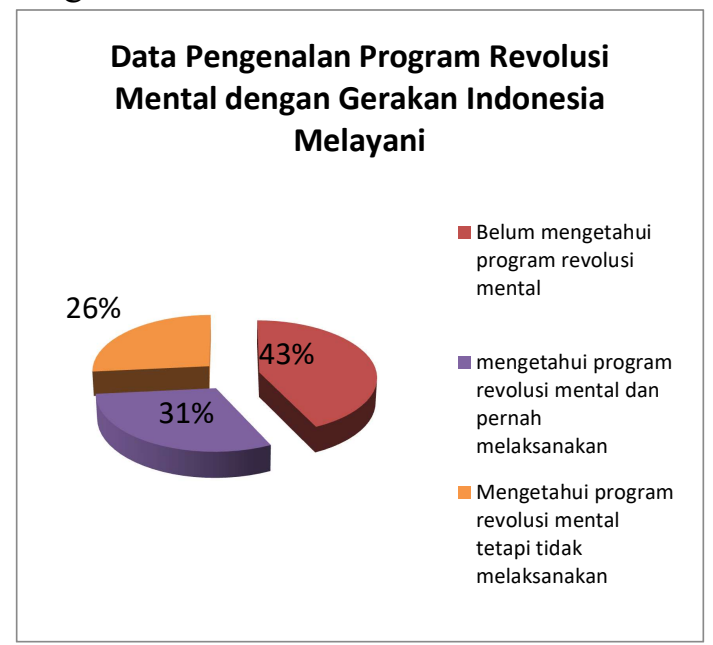

Gambar 2. Presentase Pengenalan Warga Desa Monomulyo Tentang Program Revolusi Mental

Pada tahap sosialisasi ini diberikan gambaran singkat terkait tentang pentingnya penerapan program Revolusi mental yang berawal dari permasalahan masyarakat Indonesia dalam aspek pelayanan publik. Jumlah warga yang datang mengikuti sosialisasi sebanyak 49 orang. Berdasarkan data diatas diketahui jumlah warga yang belum mengetahui program revolusi mental sebanyak 43\% yaitu 21 orang, untuk yang sudah mengetahui program revolusi mental tetapi tidak melaksanakan di kehidupan sehari sebanyak $26 \%$ yaitu sebesar 13 orang, sedangkan warga yang mengetahui dan melaksanakan program revolusi mental sebesar $31 \%$ yaitu sebanyak 15 orang. Diketahui bahwa yang telah mengetahui rata-rata warga yang memiliki pekerjaan sebagai pegawai negeri sipil dan perangkat desa. Diketahui juga warga yang belum mengetahui adanya program revolusi mental dikarenakan pekerjaan berkebun, petani dan petambang dan jarang melihat media informasi seperti internet maupun televisi. Disini peran mahasiswa dibimbing oleh dosen pembimbing menjadi agen edukasi memberikan pengetahuan dan informasi terkait program revolusi mental yang digalakkan oleh pemerintah sekarang ini. Gerakan Indonesia Melayani akan melaksanakan perbaikan fasilitas masyarakat yang sering digunakan dan dimanfaatkan masyarakat. Berdasarkan obsservasi dan pengamatan banyak fasilitas desa yang kurang layak dan tidak ada perbaikan secara bergotong royong oleh masyarakat maupuan dari perangkat desa.

\section{Tahap Pendampingan}

kegiatan pendampingan pengabdian masyarakat yang dilakukan pada desa Wonomulyo kecamatan Tanjung Palas Timur dimana kegiatan meliputi Perbaikan fasilitas olahraga desa Wonomulyo, Perbaikan Rumah Ibadah, Peremajaan Jembatan Desa dan Desain Jembatan, Pembuatan plang Desa dan Sekolah.
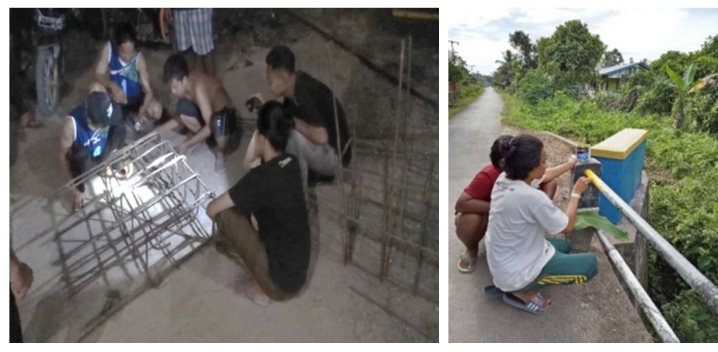

Gambar 3. Desain Rangka Perbaikan Jembatan Yang Rusak dan Peremajaan Jembatan Desa Merupakan Akses Jalan Yang Menghubungkan Dengan Desa Lainnya

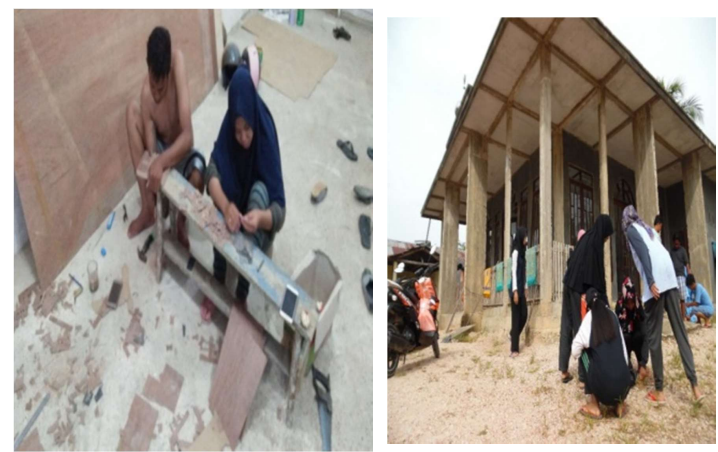

Gambar 4. Perbaikkan Salah Satu Rumah Ibadah dan Membersihan Halaman Rumah Ibadah Yang Mulai Rusak dan Kotor Dibeberapa Bagian Sudut Rumah Ibadah 


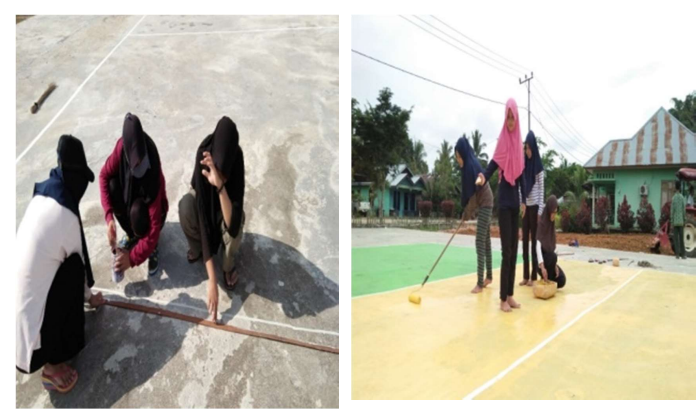

Gambar 5. Perbaikkan Salah Satu Fasilitas Olahraga Yang Sering Digunakan Oleh Masyarakat Desa
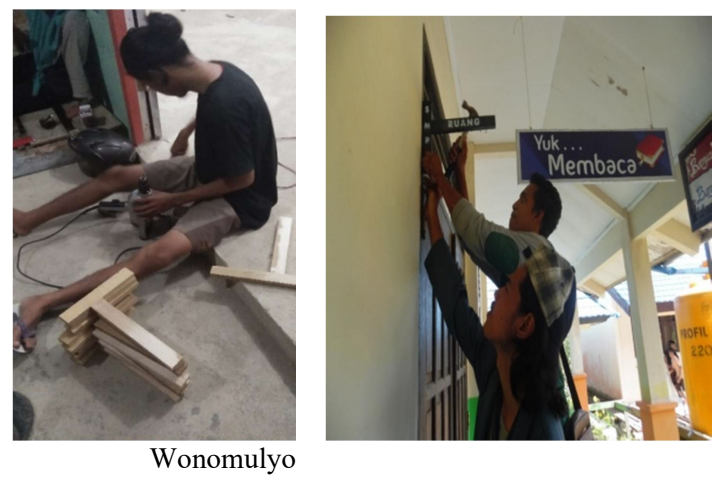

Gambar 6. Perbaikkan Papan Nama (plang) Kantor Desa, Sekolah dan Balai Adat

Dalam Pelaksanaan program revolusi mental gerakkan Indonesia Melayani juga memuat Perbaikan fasilitas olahraga desa Wonomulyo, Perbaikan Rumah Ibadah, Peremajaan Jembatan Desa dan Desain Jembatan, Pembuatan plang Desa dan Sekolah. Bersama dosen pendamping memberikan pengetahuan tentang yang meliputi Kesadaran merawat fasilitas Desa yang digunakan untuk kebersamaan dan pentingnya gerakan revolusi mental. Berdasarkan Hasil survei masyarakat mengetahui kegunaan fasilitas desa untuk kebersamaan tetapi enggan merawat, dan masyarakat kurang sadar dalam menjaga dan merawat fasilitas Desa. Sedangkan masyarakat yang peduli tetapi tidak melakukan kesadaran memperbaiki juga lumayan banyak. Dpat dilihat pada Gambar 7.

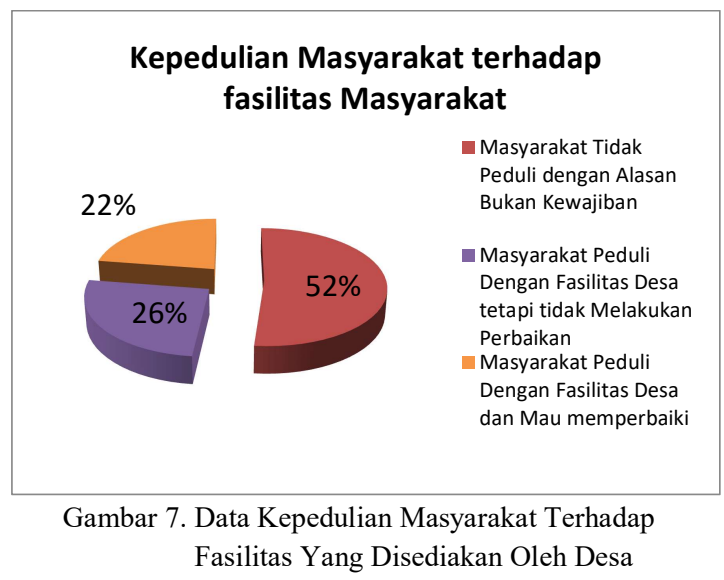

Pada prinsipnya semua program kerja baik program pengabdian yang dilaksanakan berjalan dengan lancer dan baik, namun terdapat beberapa hambatan yang dihadapi dalam masyarakat, diantaranya:

a. Kurangnya kepedulian dan kepekaan masyarakat terhadap lingkungan dan sosial setempat.

b. Kurangnya pengetahuan masyarakat tentang program kerja yang akan dilaksanakan.

c. Adanya kesibukan ketua-ketua RT sehingga susah untuk bertemu dan berkoordinasi serta dikumpulkan dalam beberapa agenda kegiatan.

d. Keterlambatan dana dan keterbatasan dalam pelaksanaan program kerja.

\subsection{Tahap Desiminasi Hasil dan Membangun Social Public Networking}

Kegiatan terakhir merupakan desiminasi adalah kegiatan memberikan informasi tentang hasil yang diperoleh dari kegiatan pendampingan selama pelaksanan pembelajaran dalam Pelaksanaan program revolusi mental gerakkan Indonesia Melayani. Selain melakukan desiminasi, tim IbM juga membangun kerjasama dengan program Social public networking, diharapkan dengan adanya bertukar pengalaman dan ilmu antara mahasiswa, 
dosen-warga dalam bentuk "Perbaikan Fasilitas masyarakat ", Dosen dan mahasiswa menjadi agen edukasi di desa binaan sesuai bidang dan keahliannya. Tidak hanya berupa menjadi agen of change, juga membimbing dalam pengetahuan teknologi dalam pembelajaran yang berbasis potensi lokal.

Berdasarkan data kepuasan dan pemahaman gerakan revolusi mental Indonesia bersih, maka kemudian dilakukan wawancara kepada masyarakat dan perangkat desa hasilnya masyarakat puas dan sudah memahami gerakan revolusi mental Indonesia melayan. Wawancara berisi tentang metode yang dominan dilakukan oleh masyarakat dan perangkat desa yang terlibat. Berdasarkan hasil data masih banyak masyarakat dan perangkat desa yang menggunakan puas dan memahami gerakan revolusi mental Indonesia melayani sebanyak 95\%. Dari Kegiatan tersebut perlunya tindak lanjut dan kegiatan yang berkesinambungan, agar masyarakat dapat merasakan dampak dan manfaat yang massif serta menyeluruh disetiap masyarakat.

Gerakan Indonesia Melayani (GIM) dalam aksi revolusi mental ini selain memberikan manfaat kepada masyarakat, dan juga memuat nilai-nilai strategis instrumental revolusi mental yaitu Integritas dan Etos Kerja. Nugroho dan Vlorensius (2018) menyatakan, gerakan Indonesia Melayani memuat nilai Integritas, dimana nilai tersebut merupakan kesatuan kata dan perbuatan yang mengarahkan karakter dan perilaku seseorang secara bertanggung jawab. Gerakan Indonesia Melayani memuat nilai Integritas, dimana nilai tersebut merupakan kesatuan kata dan perbuatan yang mengarahkan karakter dan perilaku seseorang secara bertanggung jawab. Bentuk penjabaran nilai integritas antara lain dapat dipercaya, sadar hak dan kewajiban, serta bertanggungjawab melalui media informasi publik.

\section{PENUTUP}

Kegiatan Integrasi Pemberdayaan Mahasiswa Sebagai kegiatan pengabdian Dengan Masyarakat Desa Wonomulyo Kabupaten Bulungan Melalui Program Perbaikan fasilitas Masyarakat berbasis Revolusi Mental Indonesia Melayani berjalan dengan baik dan berdasarkan hasil data masih banyak masyarakat dan perangkat desa yang menggunakan puas dan memahami gerakan revolusi mental Indonesia melayani mencapai 95\%. PKM perbaikkan fasilitas masyarakat dengan gerakan Indonesia melayani terfokus pada tingkat kesadaran menjaga dan memperbaiki fasilitas masyarakat yang di kelola oleh desa dan Peningkatan kualitas sarana dan prasarana, kegiatan tersebut mengandung nilai-nilai strategis instrumental revolusi mental yaitu Integritas, gotong royong dan etos kerja.

\section{UCAPAN TERIMAKASIH}

Dalam penulisan dan pelaksanaan pengabdian ini kami tak lupa mengucapkan terimakasih kepada Rektor dan LPPM Universitas Borneo Tarakan yang telah memberikan dana hibah pengabdian untuk mensupport terlaksananya pengabdian di wilayah Kecamatan Tanjung Palas Timur, Desa Wonomulyo. Dan terimakasih kepada tim pengabdiann yang telah bekerja sama melaksanakan pengabdian ini sampai selesai.

\section{DAFTAR RUJUKAN}

Nugroho, Endik Nugroho. Vlorensius. 2018. Pemberdayaan Masyarakat Desa Long Bila Dan Desa Pulau Sapi Kabupaten Malinau Melalui 
Optimalisasi Potensi Lokal Melalui Revolusi Mental Mewujudkan Desa Mandiri Dan Melayani. JPMB. Vol 2, No1. LPPM UBT.

Katalog Badan Pusat Statistik. 2017. Kecamatan Tanjung Palas Timur
(Halaman 51-59)

desa Wonomulyo Dalam Angka 2016. BPS. Kabupaten Bulungan.

Katalog Badan Pusat Statistik. 2018. Kalimantan Utara Dalam Angka 2018. BPS Provinsi Kalimantan Utara. 